The shortest wave-length that can be reflected depends on, amongst other things, the density of electrification ; and there is therefore a lower limit to the wave-lengths which may be used for long distance communication. The limiting wave-lengths which penetrate the ionosphere without return to earth vary from somewhat less than 10 metres for a summer noon to 23 metres for a winter night.

Since the propagation of waves to long distances is so dependent upon the state of electrification of the upper atmosphere, any variations in this electrification produce variability in the wave transmission, and as experience shows, the effect is more marked with short than with long waves. The electrification of the ionosphere is not only subject to diurnal and seasonal variations; it is also profoundly affected by changes in solar activity, with its accompanying production of magnetic storms and auroral displays. Much speculation has taken place as to the means by which the appearance of a group of sunspots influences the earth's magnetic field and produces auroræ. On one hand, Birkeland and Størmer, the Norwegian investigators, have suggested that streams of electrified particles are shot with great speed from the sun and, on reaching the earth's atmosphere, give rise to intense circulating currents resulting in the effects observed. The tracks of the charged particles will be influenced by the earth's magnetic field so as to intensify the magnetic and auroral phenomena in polar regions. Within the last few years, however, Maris and
Hulbert, rejecting the corpuscular theory, have suggested that all the observed effects may be due to the arrival in the upper atmosphere of intense ultra-violet radiation emitted from abnormally hot spots on the sun's surface.

Whatever may be the means by which the occurrence of solar activity is conveyed to the earth, there is little doubt as to the effects observed. The electrical currents circulating in the upper atmosphere induce corresponding currents in the earth, and these in turn affect cable communication, which is always worked with an earth return circuit. Although cable engineers have devised methods of mitigating the influence of these spurious signals, there are still occasions, particularly in years of sunspot maximum, when the effects are so strong and variable that many services are put out of action. In wireless trans. mission, the influence of solar activity is even more marked, particularly on the shorter wave-lengths. The result is almost always to produce an increased absorption of the waves during their passage through the atmosphere, which may be sufficient to interrupt communication completely for days at a time. In view of the comparatively immature state of short-wave technique, there is little doubt that, as a result of the research now being vigorously pursued by both the physicist and the communications engineer, considerable improvement in long-distance communication will accompany more complete knowledge of the relations between the sun and the earth.

\title{
The Baffin Bay Earthquake
}

A GREAT earthquake was recorded on the night of November 20 at West Bromwich, Kew and other observatories. The first tremors reached Kew at $11 \mathrm{~h} .38 \mathrm{~m}$. 24s., p.m., and the disturbance registered there was of an intensity that is reached only about ten times a year. The record shows that the epicentre lay about 2,400 miles north-north-west of Kew, in Baffin Bay, and this determination is supported by records at Bombay (distant 5,700 miles) and in the Canadian observatories.

The interest of the earthquake lies in the fact that it occurred in a district hitherto supposed to be free from earthquakes, and this has led to the suggestion that the shock may have been caused by the fall of an unusually large meteorite. There is nothing improbable in this, for the impact of the great Siberian meteorite of June 30, 1908, produced waves that were recorded, though feebly, at Jena, distant 3,250 miles (Dr. F. J. W. Whipple, Quart. J. Roy. Met. Soc., 56, 287-301; 1930). On the other hand, the movement registered at Kew was of great magnitude, and there seem to have been no remarkable air-waves such as were recorded in 1908 by barographs in British observatories.

The recent earthquake has directed attention to the rarity of earthquakes in the polar regions. It thus seems desirable to obtain some estimate of the distribution of earthquakes in relation to latitude. The only records that are of service for this purpose are those provided by seismographs. Taking the shocks contained in the valuable "Catalogue of Earthquakes 1918-1924" edited by the late Prof. H. H. Turner (Brit. Ass. Rep., 1928, pp. 214-304) and representing by 100 the number of earthquakes in the zone between $0^{\circ}$ and $10^{\circ} \mathrm{N}$. lat., the numbers occurring within equal areas in the zones bounded by successive parallels of $10^{\circ} \mathrm{N}$. lat. are $100,430,512,1770,1541,532,130,164$ and 145. For the southern hemisphere, the corresponding figures are $413,403,234,142,87,78$, 20,17 and 0 . The large numbers for the mid north temperate zones are no doubt due chiefly to the close distribution of seismographs.

Confining ourselves to earthquakes registered more than $80^{\circ}$ from their origins, the corresponding numbers for the northern hemisphere are 100,77 , $81,108,129,136,4,19$ and 0 , and for the southern hemisphere $93,72,48,41,22,19,0,5$ and 0 . These figures thus point to a somewhat higher seismicity in the zones between $30^{\circ}$ and $60^{\circ} \mathrm{N}$. lat., while in the southern hemisphere they show a nearly regular decline southwards. Moreover, the occurrence in both polar zones of great earthquakes like that of November 20 is clearly most unusual. 